\title{
MEMBUAT APLIKASI PENYIMPANAN DAN PENGOLAHAN DATA DENGAN VB.NET
}

\author{
Deval Gusrion, S.Kom, M.Kom \\ Fakultas Ilmu Komputer Universitas Putra Indonesia "UPI-YPTK" Padang \\ e-mail : devalgusrion@gmail.com
}

\begin{abstract}
Bahasa pemograman adalah perintah-perintah atau instruksi yang dimengerti oleh komputer untuk melakukan tugas-tugas tertentu salah satunya adalah perintah untuk menyimpan dan mengolah data. Aplikasi untuk mengolah data saat ini begitu banyak, salah satunya visual studio 2010 atau yang dikenal dengan vb.net. vb.net dilengkapi dengan NET Framework. Kerangka kerja yang dibuat sedemikian rupa agar para programmer dapat mengembangkan program komputer dengan jauh lebih mudah, dan juga untuk mengurangi kerawanan aplikasi dan juga komputer dari beberapa ancaman keamanan.
\end{abstract}

Kata kunci : database, aplikasi, visual basic,data, net framework

\section{Pendahuluan}

Pada era digital saat ini, data-data disimpan bukan dalam bentuk kertas yang tersimpan dalam sebuah lemari yang tersusun rapi disudut ruangan, namun data-data tersebut disimpan dalam kumpulan file, tabel, atau arsip yang saling terhubung yang disimpan dalam media elektronik, di era digital ini kita mengenalnya dengan database. Database merupakan sebuah wadah untuk menyimpan data, dan untuk menyimpan data kedalam wadah tersebut kita membutuhkan sebuah perangkat atau tool, tool tesebuat adalah bahasa pemograman. Bahasa pemograman untuk mengolah dan menyimpan data saat ini begitu banyak, salah satunya visual studio 2010 atau yang dikenal dengan vb.net. Visual Studio 2010 (vb.net) dilengkapi dengan NET Framework. Kerangka kerja yang dibuat sedemikian rupa agar para programmer dapat mengembangkan program komputer dengan jauh lebih mudah, dan juga untuk mengurangi kerawanan aplikasi dan juga komputer dari beberapa ancaman keamanan.

\section{Landasan Teori}

\subsection{Visual Studio 2010 (vb.net)}

Visual Studio 2010 (yang sering juga disebut dengan VB .Net 2010) pada dasarnya adalah sebuah bahasa pemrograman komputer. Dimana pengertian dari bahasa pemrograman itu adalah perintah-perintah atau instruksi yang dimengerti oleh komputer untuk melakukan tugas- 
VB .Net 2010 selain disebut dengan bahasa pemrograman, juga sering disebut sebagai sarana (tool) untuk menghasilkan program-progam aplikasi berbasiskan windows. VB.Net 2010 bahasa yang cukup mudah untuk dipelajari, bagi programer pemula yang baru ingin belajar program, lingkungan Visual Studio dapat membantu membuat program dalam sekejap mata, karena bahasa Visual Studio cukup sederhana dan menggunakan kata-kata bahasa Inggris yang umum digunakan. Kita tidak perlu lagi menghafalkan sintaks-sintaks maupun format- format bahasa yang bermacam-macam, di dalam Visual Basic semuanya sudah disediakan dalam pilihan-pilihan yang tinggal diambil sesuai dengan kebutuhan. Sedangkan bagi programer tingkat lanjut, kemampuan yang besar dapat digunakan untuk membuat program- program yang kompleks, misalnya lingkungan net-working atau client server. Beberapa keistimewaan Visual Studio 2010 ini diantaranya seperti :

- Menggunakan platform pembuatan program yang dinamakan developer studio, yang memiliki tampilan dan sarana yang sama dengan Visual C++ dan Visual J++. Dengan begitu Anda dapat bermigrasi atau belajar bahasa pemrograman lainnya dengan mudah dan cepat.

- Memiliki compiler handal yang dapat menghasilkan file executable yang lebih cepat dan lebih efisien dari yang sebelumnya.

- Memiliki beberapa tambahan wizard yang baru. Wizard adalah sarana yang mempermudah di dalam pembuatan aplikasi dengan mengotomisasi tugas-tugas tertentu.

- Visual Studio 2010 mempunyai beberapa fitur untuk pengembangan berbagai macam aplikasi yang diantaranya; Windows Development, Web Development, Office Development, Sharepoint Development, Cloud Development (Windows Azure), Silverlight Tooling, Multi-Core Development, Customizable IDE.

\subsection{Database MySQL}

Basis data (database) adalah kumpulan suatu informasi yang disimpan didalam komputer secara sistematik dimana suatu informasi tersebut dapat diperiksa menggunakan suatu program komputer untuk memperoleh informasi. Ada beberapa perangkat lunak atau software open source yang disediakan untuk membuat suatu basis data. perangkat lunak tersebut merupakan suatu pemrograman yang dikategorikan sebagai bahasa pemrograman tingkat tinggi (high level language) salah satunya adalah mySQL. Data base MySQL dapat dibuat menggunakan tampilan phpmy admin atau menggunakan sebuah script dalam PHP.

MySQL merupakan sebuah perangkat lunak /software sistem manajemen basis data SQL atau DBMS Multithread dan multi user. MySQL sebenarnya merupakan turunan dari salah satu konsep utama dalam database untuk pemilihan atau seleksi dan pemasukan data yang memungkinkan pengoperasian data dikerjakan secara mudah dan otomatis. Adapun kelebihan MySQl dalam penggunaanya dalam database adalah:

- Gratis sehingga MySQL dapat dengan mudah untuk mendapatkannya

- MySQL stabil dalam pengoprasiannya

- MySQL mempunyai sistem keamanan yang cukup baik

- Sangat mendukung transaksi dan mempunyai banyak dukungan dari komunitas

- Sangat fleksibel dengan berbagai macam program

- Perkembangan dari MySQl sangat cepat 


\subsection{Net Framework}

Net Framework Adalah sebuah perangkat lunak (Software) yang digunakan terutama pada Sistem Operasi Microsoft Windows. .Net Framework merupakan suatu lingkungan kerja untuk memudahkan pengembangan dan eksekusi berbagai macam bahasa pemrograman dan kumpulan library agar dapat bekerja sama dalam menjalankankan aplikasi berbasis Windows. Umumnya komputer hanya memiliki satu bahasa yaitu (assembly), maka ketika anda mendeveloved sebuah aplikasi dengan bahasa .Net komputer tidak akan memahami bahasa tersebut. Oleh sebab itu diperlukan sebuah software (penerjemah) untuk bisa menjalankannya. Tidak heran beberapa software tidak bisa berjalan dengan baik (error) pada sebuah komputer jika bahasa yang digunakannya berbeda. Itulah gunanya menggunakan .Net Framework sebagai penerjemah bahasa tersebut. Inilah funggsi utama dari .Net Framework yaitu sebagai penerjemah atau mengeksekusi sebuah software agar dapat dijalankan. Biasanya pada sebuah sistem operasi dalam hal ini windows biasanya sudah terdapat .Net Framework, namun belum tentu software tersebut aktif dan dapat digunakan, untuk itu dalam beberapa sistem operasi windows perlunya install / aktifkan secara manual.

\subsection{Crystall Report}

Crystal Reports merupakan salah satu paket program yang digunakan untuk membuat, menganalisa, dan menterjemahkan informasi yang terkandung dalam database ke dalam berbagai jenis laporan. Crystal Reports dirancang untuk membuat laporan yang dapat digunakan dengan berbagai bahasa pemrograman berbasis Windows, seperti Visual Basic, Visual $\mathrm{C} / \mathrm{C}++$, Visual Interdev, dan Borland Delphi. Dan yang saya pakai itu, Crystal Report untuk Visual Studio 2010. Beberapa Kelebihan dari Crystal Report adalah sebagai berikut :

1. Pembuatan laporan dengan Crystal Reports tidak terlalu rumit dan banyak melibatkan kode program.

2. Program Crystal Reports banyak digunakan karena mudah terintegrasi dengan bahasa lain.

3. Fasilitas impor hasil laporan yang mendukung format-format paket program lain, seperti Microsoft Office, Adobe Acrobat Reader, HTML, dan sebagainya.

4. Koneksi yang mudah karena disertai beberapa form yang memudahkan koneksi.

\section{Metodologi Penelitian}

Metodologi penelitian yang digunakan meliputi:

a. Analisis

1. Melakukan survei terhadap sistem yang sedang berjalan dengan cara wawancara terhadap pelaku penguna bahasa pemograman, kemudian menganalisis hasil survei tersebut untuk mendapatkan rumusan masalah yang sedang dihadapi oleh mahasiswa dan mendapatkan alternatif pemecahan masalah, yang dapat dengan segera dijalankan.

2. Studi Literatur yang merupakan teknik pengumpulan data atau informasi dengan mempelajari buku yang berisi konsep dan implementasi bahasa pemograman visual studio (VB.Net) sebagai dasar dari pengembangan penulisan naskah ini.

b. Perancangan

Perancangan program dengan menggunakan visual studio 2010 (vb.net) dengan laporan mengunakan aplikasi crytall report beserta database Mysql yang akan digunakan dalam implementasi ini. 
UPI YPTK Jurnal KomTekInfo Vol. 5, No. 1, Juni 2018, Hal.150-163 ISSN :2356-0010 | eISSN :2502-

8758 Copyright $\bigcirc 2018$ by LPPM UPI YPTK Padang

c. Implementasi

Membuat sebuah studi kasus berupa program perpustakaan

d. Pengujian Simulasi

aplikasi yang sudah disimulasi akan diuji untuk melihat bagaimana kinerjanya dan kemudian mengevaluasinya. Dengan evaluasi ini diharapkan solusi yang didapat, akan segera untuk diimplementasikan di lapangan.

\section{Impelementasi}

Jurnal yang disusun ini dengan judul cara cepat membangun aplikasi dengan visual studio 2010 (vb.net) akan mengambil contoh berupa aplikasi perpustakaan dengan nama databasenya adalah dbpustaka. Adapun struktur tabel dari taplikasi perpustakaan terdiri dari : tabel anggota, tabel buku, tabel petugas, tabel pinjam, tabel detail pinjam, tabel kembali dan tabel detail kembali. Adapun bentuk normalisati dari dbperbustakaan tersebut adalah sebagai berikut :

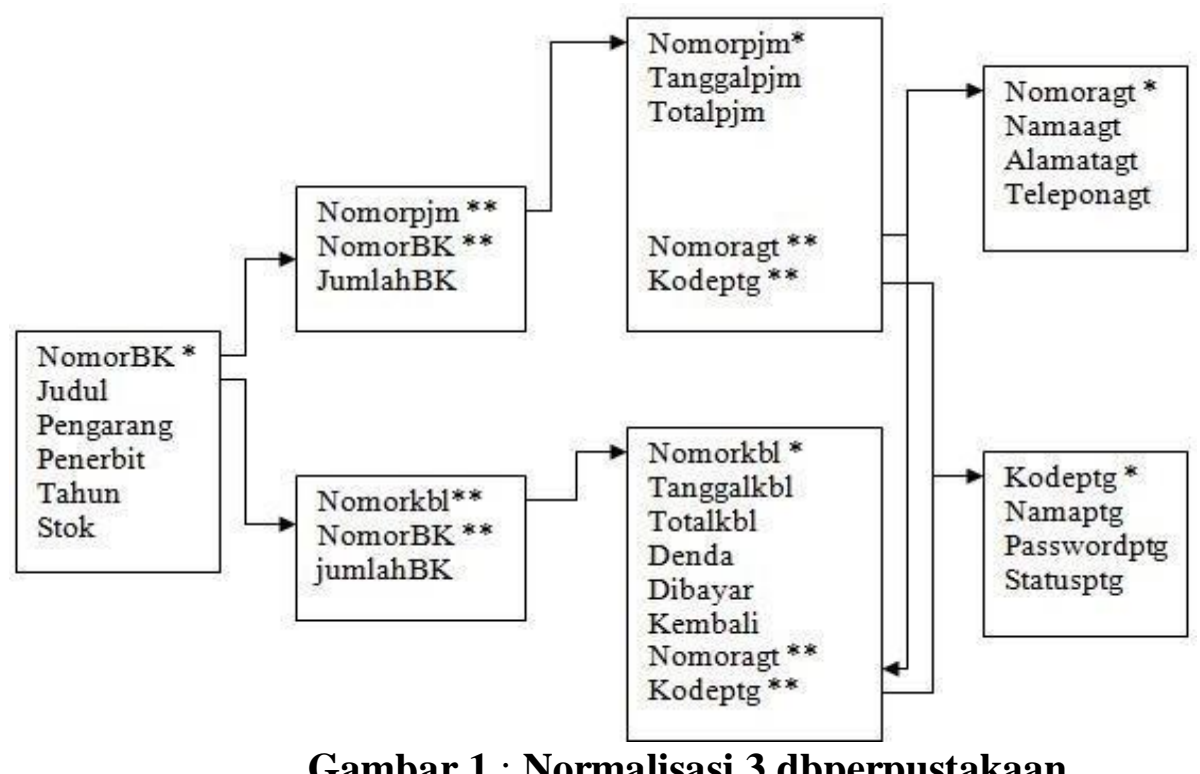

Gambar 1 : Normalisasi 3 dbperpustakaan

\subsection{Pembuatan Database}

Aplikasi perpustakaan mengunakan database MySQL sebagai media penyimpanannya, dalam kasus ini database dapat diakses melalui browser : http://localhost/phpmyadmin, setelah dibuat database kemudian kita create tabel sesuai dengan yang telah di normalisasikan seperti gambar diatas

\begin{tabular}{|c|c|c|c|c|c|c|c|c|c|c|c|c|c|c|}
\hline & Field & Type & Collation & Attributes & Null & Default & Extra & \multicolumn{7}{|c|}{ Action } \\
\hline 口 & Nomoragt & $\operatorname{varchar}(4)$ & latin1_swedish_ci & & No & & & 闻 & 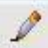 & $x$ & 唒 & 可 & 貉 & 圆 \\
\hline 回 & Namaagt & $\operatorname{varchar}(30)$ & latin1_swedish_ci & & No & & & 坥 & $\theta$ & $x$ & 實 & 可 & 聂 & 粗 \\
\hline$\square$ & Alamatagt & $\operatorname{varchar}(30)$ & latin1_swedish_ci & & No & & & 闻 & $\theta$ & $x$ & 閉 & 闹 & 䀪 & 粗 \\
\hline$\square$ & Teleponagt & $\operatorname{varchar}(15)$ & latin1_swedish_ci & & No & & & 国 & $\theta$ & $x$ & 配 & 可 & 眵 & 粗 \\
\hline
\end{tabular}

Gambar 2 : Tabel Anggota 
UPI YPTK Jurnal KomTekInfo Vol. 5, No. 1, Juni 2018, Hal.150-163 ISSN :2356-0010 | eISSN :25028758 Copyright@2018 by LPPM UPI YPTK Padang

\begin{tabular}{|c|c|c|c|c|c|c|c|c|c|c|c|c|c|}
\hline Field & Type & Collation & Attributes & Null & Default & Extra & \multicolumn{7}{|c|}{ Action } \\
\hline NomorBK & $\operatorname{varchar}(4)$ & latin1_swedish_ci & & No & & & 罒 & $\Rightarrow$ & $x$ & 閉 & 闰 & 䦨 & 初 \\
\hline Judul & varchar(30) & latin1_swedish_ci & & No & & & 闻 & $\Leftrightarrow$ & $x$ & 䦤 & 闰 & 咸 & 㵽 \\
\hline Pengarang & varchar(30) & latin1_swedish_ci & & No & & & 闻 & $\Rightarrow$ & $x$ & 閐 & 闰 & 妇 & 臣 \\
\hline Penerbit & $\operatorname{varchar}(30)$ & latin1_swedish_ci & & No & & & 闻国 & $\Leftrightarrow$ & $x$ & 闌 & 閘 & 聄 & 㢈 \\
\hline Tahun & varchar(12) & latin1_swedish_ci & & No & & & 㘣圆 & $\Leftrightarrow$ & $x$ & 闌 & 间 & 閜 & 㯺 \\
\hline Stock & $\operatorname{int}(11)$ & & & No & & & 闻 & $\Rightarrow$ & $x$ & 阒 & 囯 & 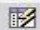 & i $T$ \\
\hline
\end{tabular}

\section{Gambar 3 : Tabel Buku}

\subsection{Pembuatan Data source}

Data source merupakan sebuah jembatan yang menghubungkan antara aplikasi VB.net dengan Database MySql (aplikasi perpustakaan dengan database dbpustaka). Adapun nantinya setelah membuat data source field-field yang akan kita butuhkan sebagai input tinggal di drag ke form yang telah disediakan. Adapun cara membuat data source sebagai berikut :

a. Ambil menu Add New Data Sources

b. Pilih Database $\rightarrow$ Dataset $\rightarrow$ New Connection $\rightarrow$ MySQL Database (sesuaikan dengan database add Connection

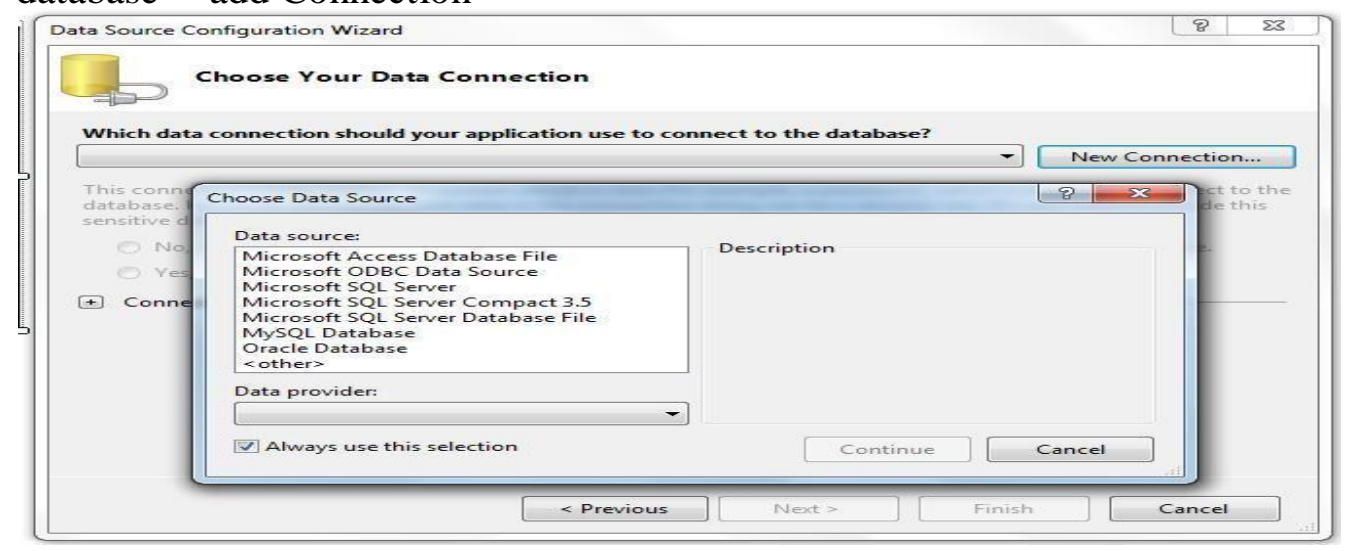

Gambar 4 : Add New Data

Source c. Add Connection $\rightarrow_{\mathrm{OK}} \rightarrow_{\text {Next }}$

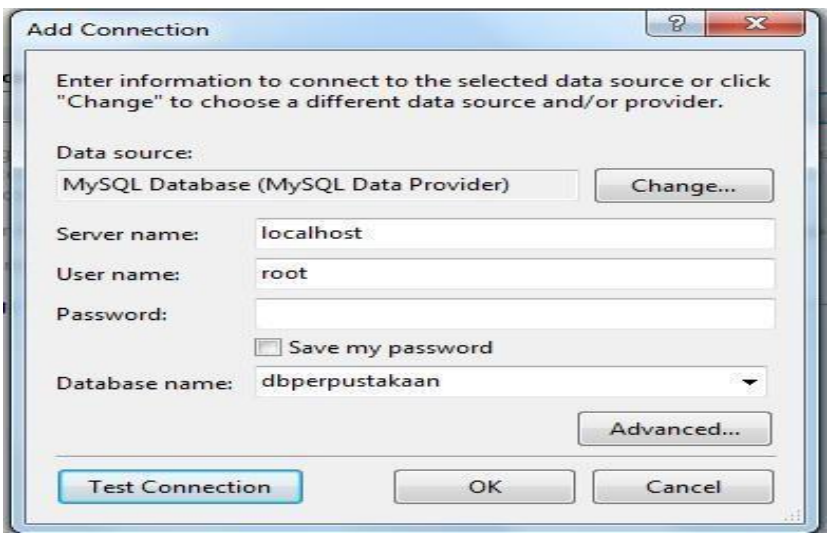

Gambar 5 : Add New Data Source 
c. Pada pilihan Choose Your Database, pilih file-file yang dibutuhkan untuk create program entry.

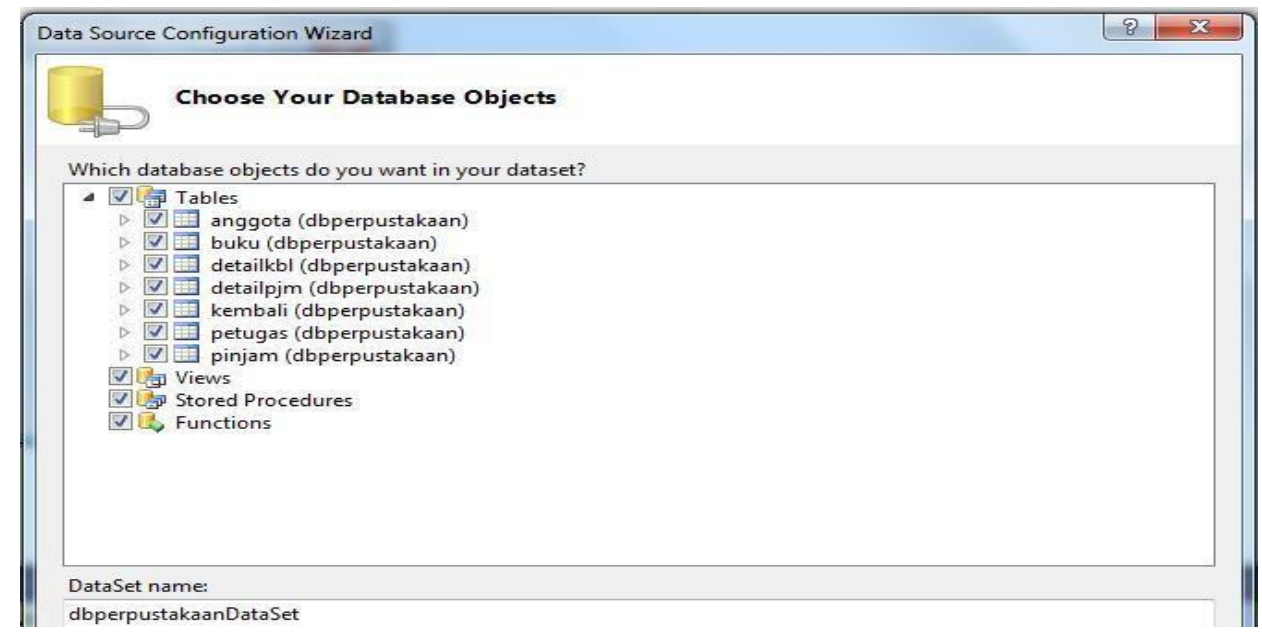

Gambar 6 : Pemilihan Objek Database

\subsection{Pembuatan Form Entri}

Setelah kita selesai membuat data sources yang merupakan sebuah jembatan antara database dbperpustakaan dengan aplikasi perpustakaan, selanjutnya membuat form-form yang dibutuhkan seperti entri anggota, buku, petugas, peminjaman dan pengembalian.

a. Entri Anggota

Gambar dibawah merupakan hasil data pembuatan data sources, ada dua jenis yaitu detail dan data grid view. Detail menampilkan field-field tabel anggota yang ada di database dan data grid view berupa tabel yang menampilkan data yang telah berhasil tersimpan dalam tabel anggota.
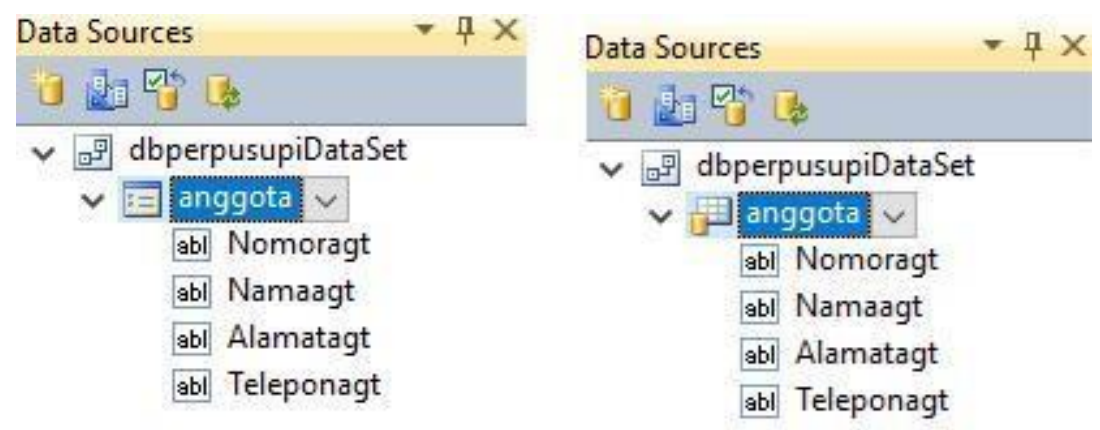

Gambar 7 : data sources dbperpustakaan

Selanjutnya detail dan data grid view di drag (ditarik ke form anggota) seperti pada gambar dibawah ini : 


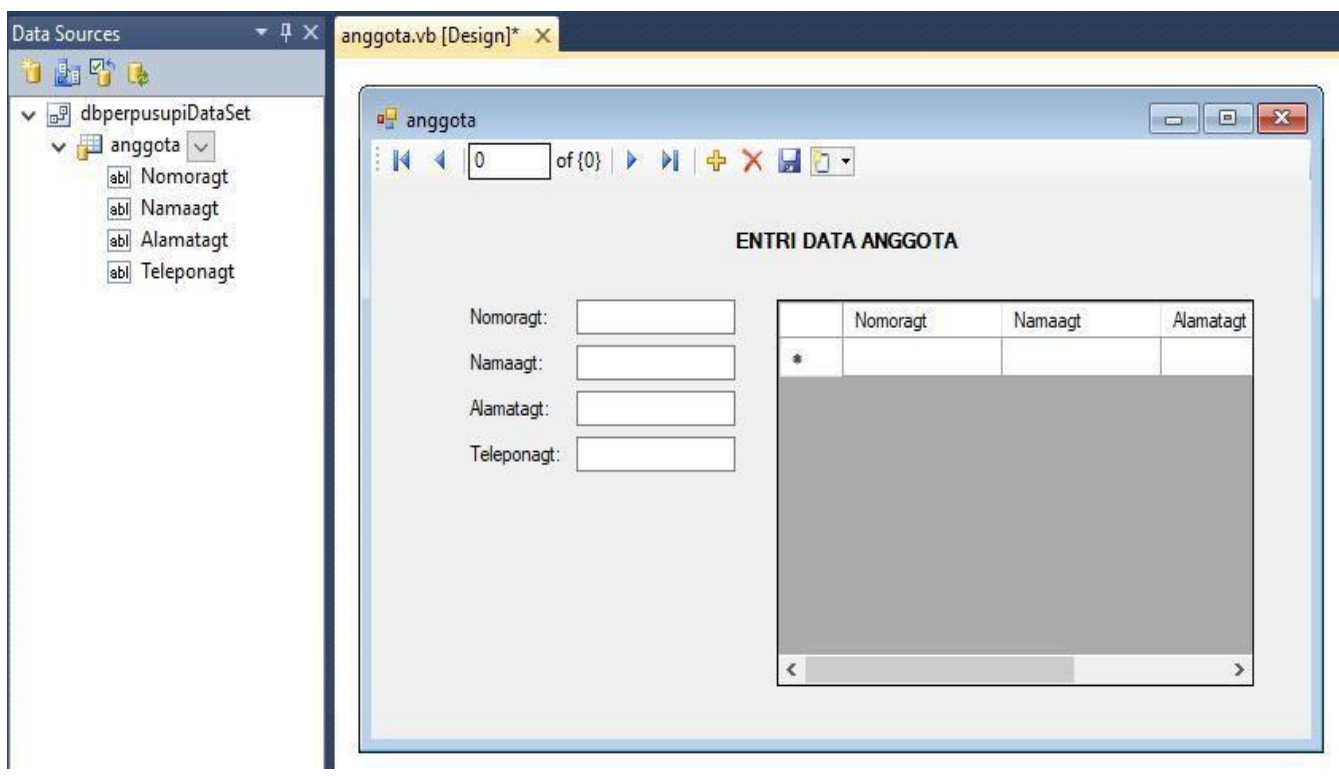

Gambar 8 : Form Entri Data Anggota

pada tahap ini kita sudah selesai membuat program input untuk tabel anggota, kita dapat melakukan penginputan data, menghapus maupun mengedit. Ada tiga rombol yang berpengaruh disini, seperti gambar dibawah ini :

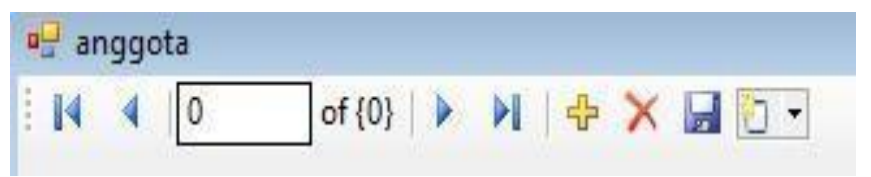

Gambar 9 : Tombol-tombol pada form

Untuk menginput data baru pertama kali yang kita lakukan adalah menekan tombol tambah (+) selanjutnya baru mengisikan data di text box yang tersedia, kemudian setelah data selesai di input di text box dilanjutkan dengan menekan tombol save (gambar seperti disket). Jika ada data yang perlu di perbaiki, kita dapat memangil data yang telah tersimpan di database, kemudian mengedit dengan data yang baru selanjutnya kembali menekan tombol save (gambar seperti disket), begitu juga untuk menghapus data, setelah kita men-searching dan mendapatkan data yag ingin di hapus langkah selanjutnya kita menekan tombol (x) dan setelah data hilang dilanjutkan dengan menekan tombol save.

b. Entri Buku

Pembutan entri buku tidak jauh berbeda dengan pembuatan form anggota, Detail menampilkan field-field tabel buku yang ada di database dan data grid view berupa tabel yang menampilkan data yang telah berhasil tersimpan dalam tabel buku. Pada detail kita dapat merubah field sesuai kebutuhan, bisa berupa combo box atau lain sebagainya sesuai kebutuhan kita seperti yang dilihatkan dalam gambar dibawah ini : 
UPI YPTK Jurnal KomTekInfo Vol. 5, No. 1, Juni 2018, Hal.150-163 ISSN :2356-0010 | eISSN :25028758 Copyright@2018 by LPPM UPI YPTK Padang

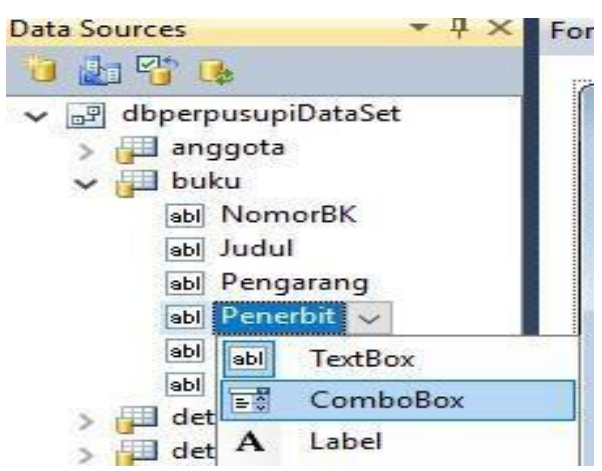

\section{Gambar 10 : Merubah Field}

Selanjutnya detail dan data grid view di drag (ditarik ke form anggota) seperti pada gambar dibawah ini :

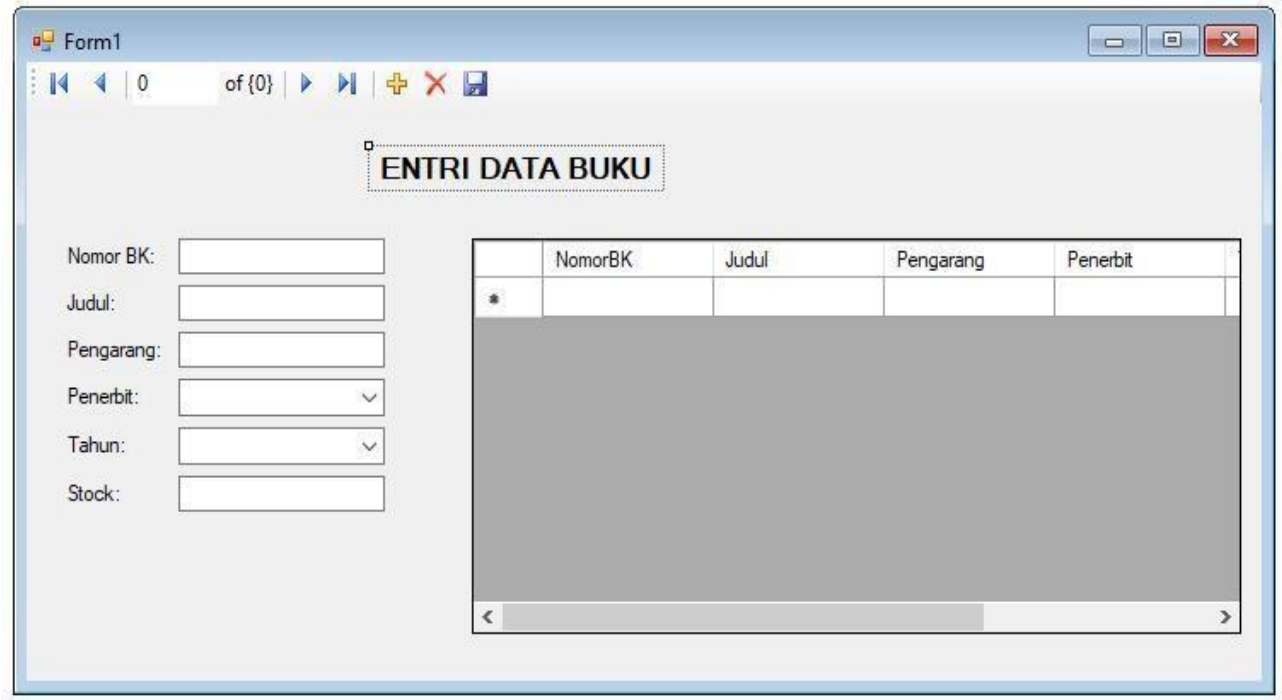

c. Form lainnya

\section{Gambar 11 : Entri Data Buku}

Entri lainnya seperti petugas, peminjaman dan pengembalian dapat dibuat dengan cara yang sama seperti diatas, dan jikapun ada memasukan isntruksi-intruksi lainnya seperti logika percabangan, perkalian bisa ditambahkan didalam form. Adapun contoh form lainnya yang dibutuhkan dalam aplikai perpustakaan adalah sebagai berikut :

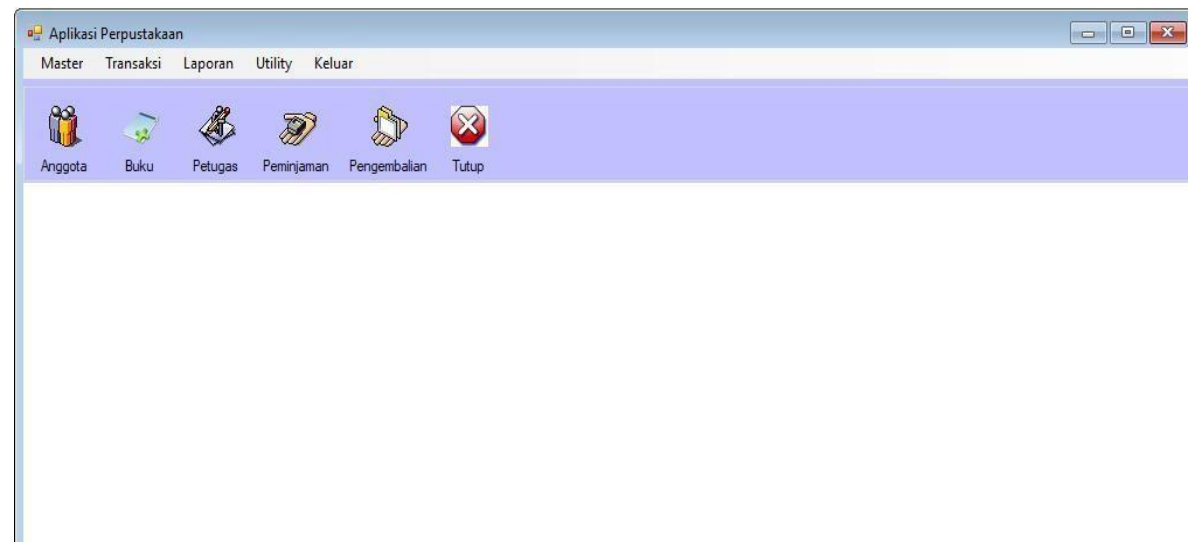


UPI YPTK Jurnal KomTekInfo Vol. 5, No. 1, Juni 2018, Hal.150-163 ISSN :2356-0010 | eISSN :25028758 Copyright $\bigcirc 2018$ by LPPM UPI YPTK Padang

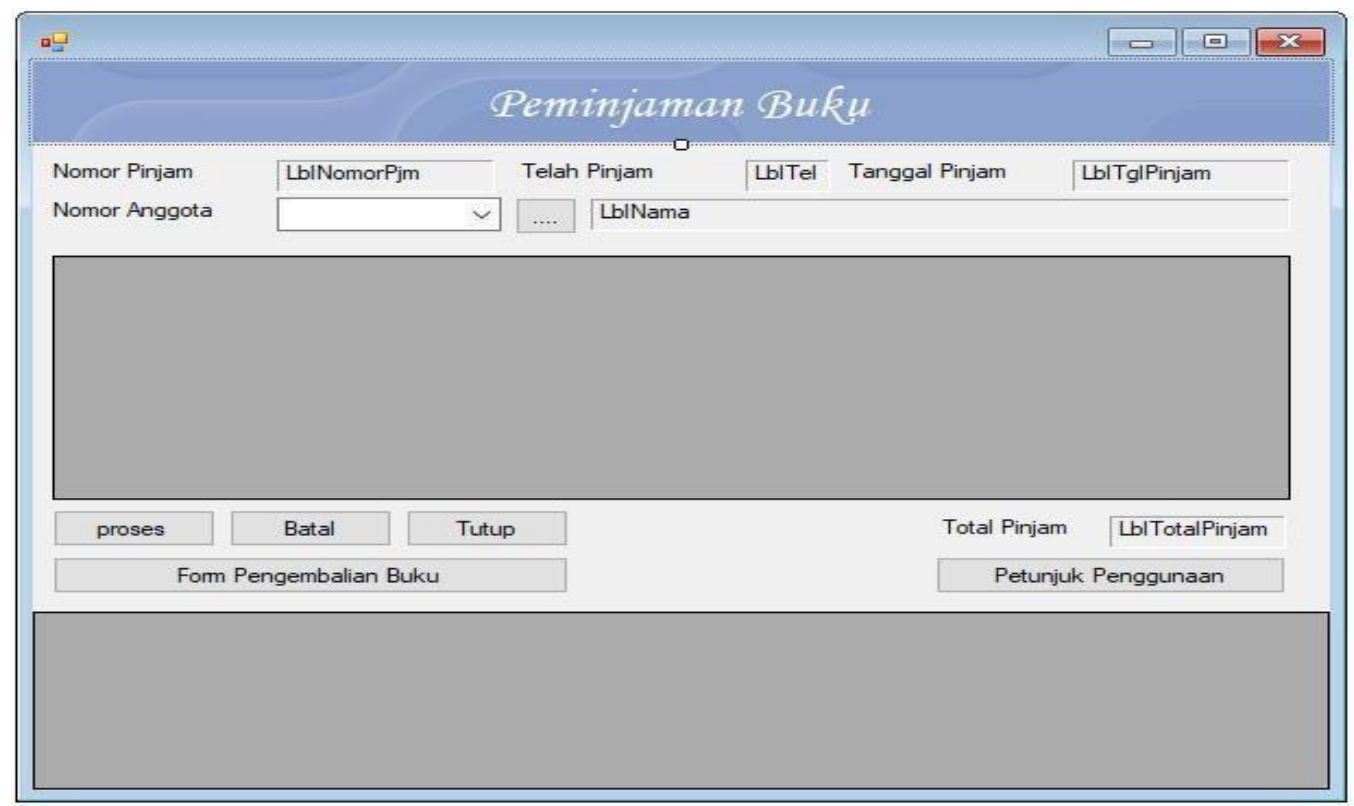

Gambar 13 : Peminjaman Buku

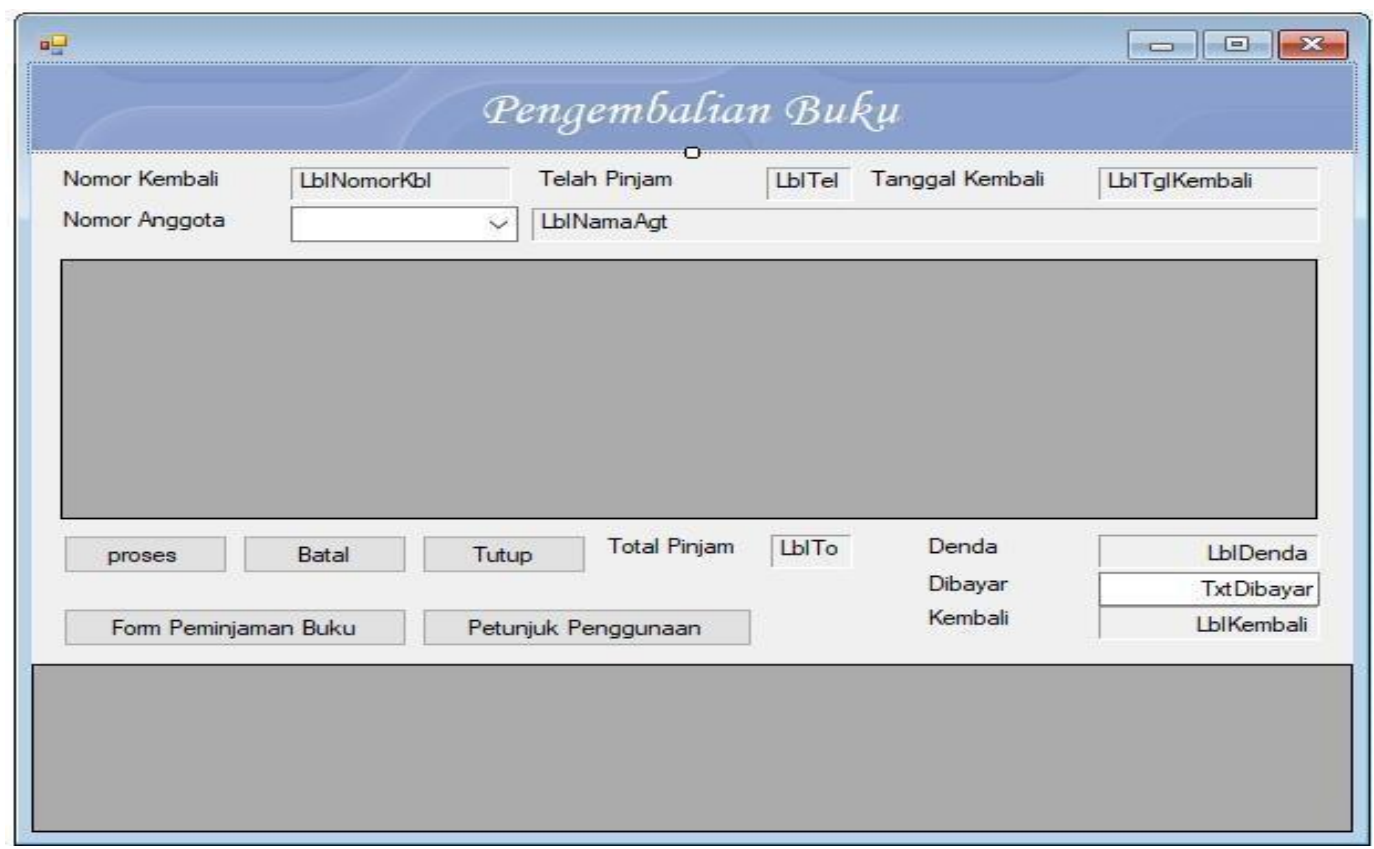

Gambar 14 : Form Pengembalian Buku

\subsection{Pembuatan Laporan}

Pembuatan laporan dalam jurnal ini mengunakan aplikasi Crystal Reports. Adapun laporan yang diperlukan nanti dari aplikasi perpustakaan ini terdiri dari laporan : laporan peminjaman, laporan pengembalian dan laporan dari jumlah anggota perpustakaan. Dapun langkah-langkah pembuatan laporannya adalah sebagai berikut : 
UPI YPTK Jurnal KomTekInfo Vol. 5, No. 1, Juni 2018, Hal.150-163 ISSN :2356-0010 | eISSN :25028758 Copyright $\bigcirc 2018$ by LPPM UPI YPTK Padang

a. Add data sources

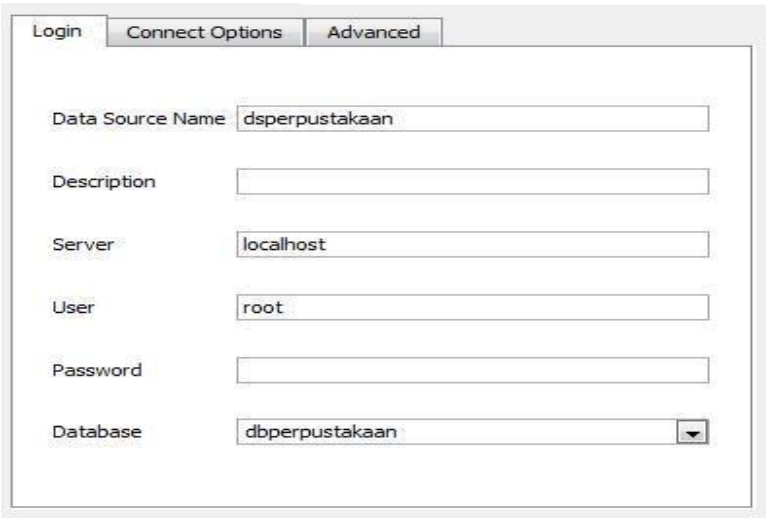

Gambar 15 : Data Sources Perpustakaan

b. Setelah mempunyai data sources, selanjutnya create new report

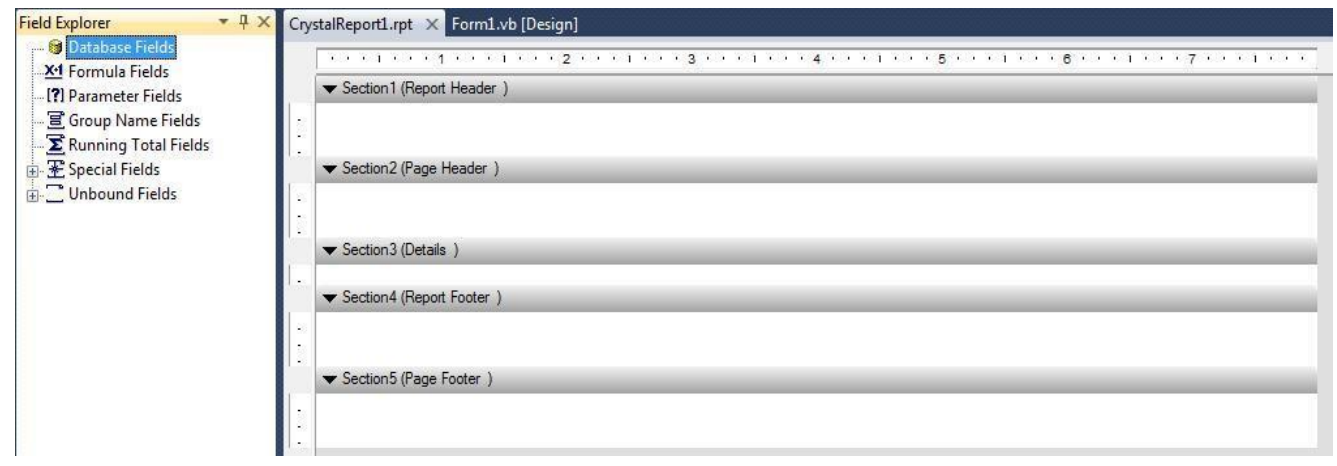

Gambar 16 : Crytall Reports

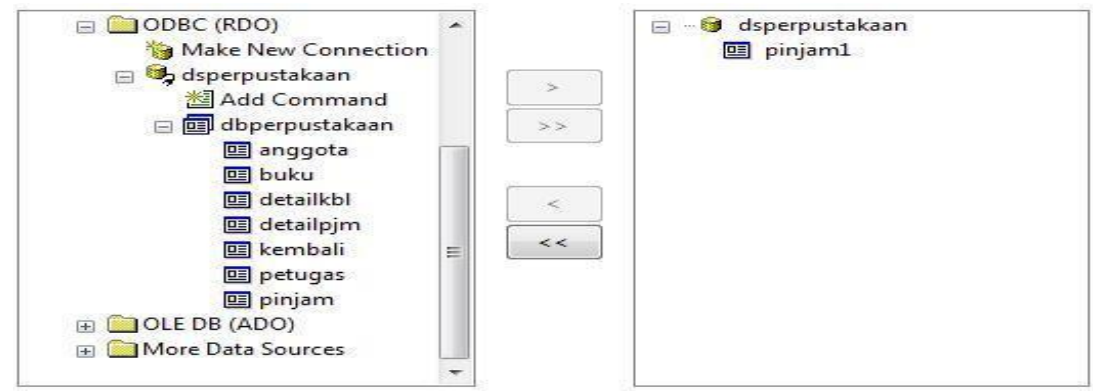

\section{Gambar 17 : New Connection ODBC}

C. Terdapat 5 section pada aplikasi crystal report, section 1 untuk judul dari laporan, section 2 untuk nama dari setiap kolom dan section 3 merupakan isi file (field/record). Kemudian tarik item-item yang ada di database field ke crystal report sesuai kebutuhan laporan kita ke section 3 (detail). 
UPI YPTK Jurnal KomTekInfo Vol. 5, No. 1, Juni 2018, Hal.150-163 ISSN :2356-0010 | eISSN :25028758 Copyright $\odot 2018$ by LPPM UPI YPTK Padang

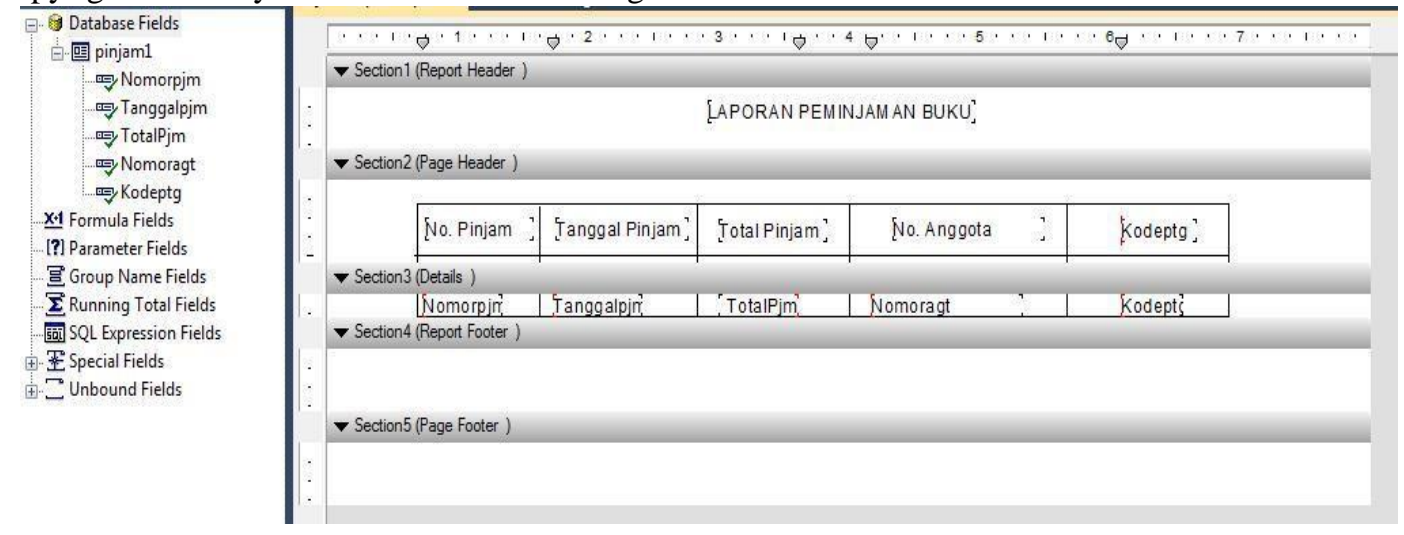




\section{Gambar 18 : LaporanPeminjaman Buku}

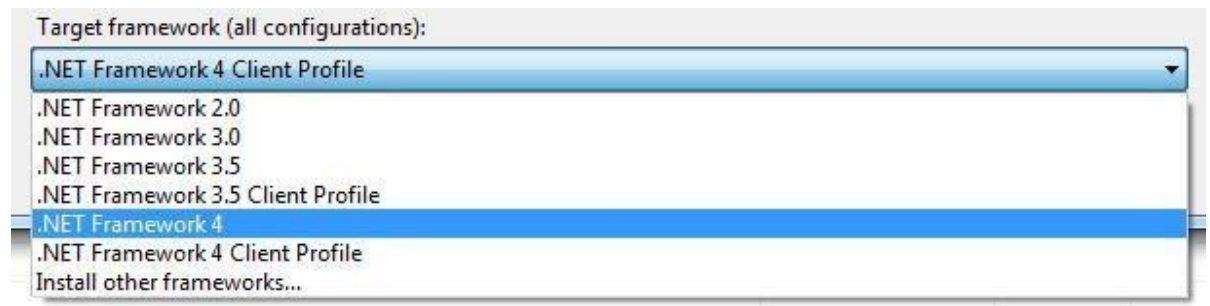

\section{Gambar 19 : Net Framework 4}

D. Setelah menganti framework menjadi .Net Framework 4, Pada tool boxt dibagian repoting akan bertambah dua item (crystall report viewer dan crystall report document) dan selanjutnya drag crystal report viewer ke form lapran yang telah kita sediakan.

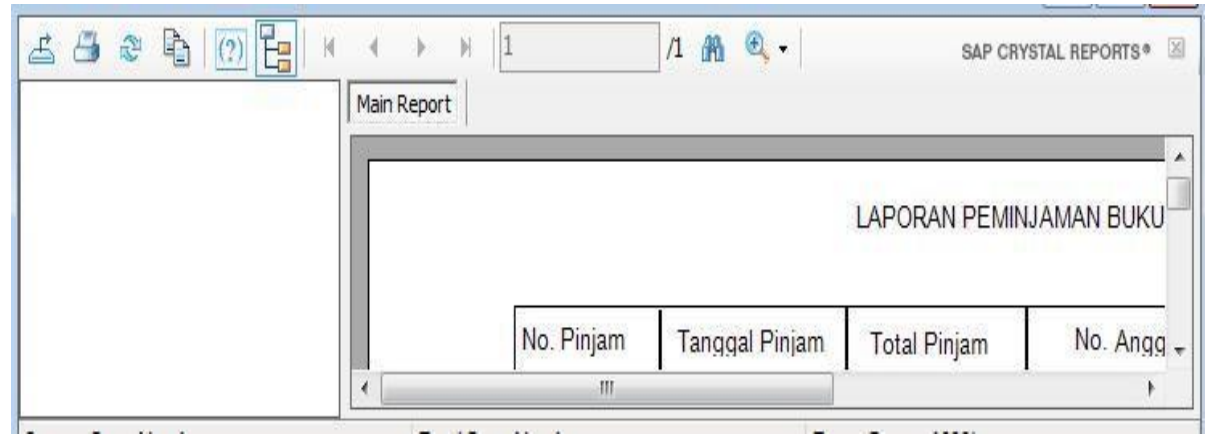

Gambar 20 : Form Laporan

E. Untuk memanpilkan data, pada crystall report viewer, pilih ReportSources sesuai dengan crystal report yang telah kita rancang.

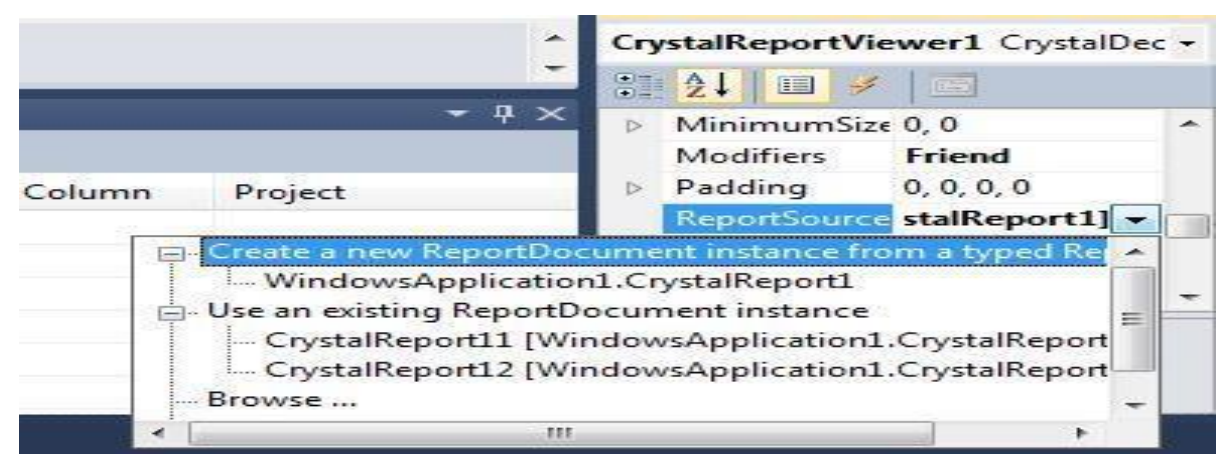

Gambar 21 : Report Sources

\section{Kesimpulan}

Perkembangan ilmu komputer begitu cepat dan semakin menawarkan kemudahan dari segi pemakaian maupun pembuatan, seperti pembuatan aplikasi mengunakan bahasa pemograman visual studio 2010 (VB.Net) ini, maka dapat ditarik kesimpulan sebagai berikut : 
UPI YPTK Jurnal KomTekInfo Vol. 5, No. 1, Juni 2018, Hal.150-163 ISSN :2356-0010 | eISSN :2502-

8758 Copyright $\odot 2018$ by LPPM UPI YPTK Padang

1. Dari pembahasan di atas dapat di simpulkan, bahwa bahasa pemograman visual studio merupakan pemrograman berbasis Windows. Visual Basic juga merupakan bahasa pemrograman Object Oriented Programming (OOP), yaitu pemrograman yang berorientasi objek. Visual Basic menyediakan objek-objek yang sangat kuat, berguna, dan mudah dipakai. Dengan fasilitas tersebut, membuat Visual Basic menjadi begitu diinginkan oleh programmer.

2. Mahasiswa atau pelajar yang menyukai bahasa pemograman mendapatkan cara baru membuat sebuah aplikasi dengan cepat, meskipun databasenya memiliki banyak file dan fields.

3. Memudahkan dosen yang mengajar bahasa pemograman visual studio VB.Net, sehingga nantinya dosen atau tenaga pengajar lebih banyak membahas studi kasus dalam pemograman.

\section{Referensi}

[1] Darmayuda,Ketut 2010, "Pemograman Aplikasi Database dengan Microsoft Visual Basic Net 2008”, Bandung : Informatika.

[2] Rusmawan, Uus 2011,"Koleksi Program VB.Net". Jakarta : Elex Media Komputindo

[3] Hidayatullah, Priyanto 2014,’Visual Basic.Net”. Bandung : Informatika.

[4] Kador, Abdul 2008,"Belajar Database Menggunakan MySQL”. Yogyakarta: Andi.

[5] Sutabri, Tata 2012, "Analisis Sistem Informasi”, Yogyakarta, Andi. 